\title{
Understanding the Context for Health Behavior Change with Cognitive Work Analysis and Persuasive Design
}

\author{
Catherine M. Burns \\ University of Waterloo \\ catherine.burns@uwaterloo.ca
}

\author{
Leila Sadat Rezai \\ University of Waterloo \\ leila.rezai@uwaterloo.ca
}

\author{
Justin St. Maurice \\ Conestoga College \\ jstmaurice@conestogac.on.ca
}

\begin{abstract}
Cognitive Work Analysis (CWA) and Persuasive Design (PD) can be complementary approaches for designing behavior change systems. CWA can provide insights into persuasive context, identify ineffective behavior paths and suggest more effective behaviors. However, PD can contribute design ideas to create that behavior change. These methods, and how they can be used together, are discussed. The example of blood pressure management is used to show how new behavior change paths can be identified and encouraged.
\end{abstract}

\section{Introduction}

Technology is a pervasive part of everyday life and is often a critical tool in helping us at work and home. Increasingly, we are asking that technology help us perform better. We ask technology to help us monitor our health, to help us exercise and eat better, and improve our performance at work. Our information technologies are partners in behavior change.

Designing technologies for behavior change, however, is an emerging science. Perspectives from the field of human factors engineering have long studied ways of improving human performance, from faster and more accurate performance to better mental models and fewer errors. These approaches have worked well in regular work environments, but break down in the more voluntary technologies such as consumer health technologies. A human factors design process may create a cognitively correct, highly usable design, but the design may be lacking in engagement and motivation. The converse situation is also true - designs for work environments that focus exclusively on engagement or gamification may be lacking in an understanding of the work processes that need to be supported. To bridge this gap, we have begun to use the methods of Cognitive Work Analysis (CWA) and Persuasive Design (PD), in concert to provide cognitively correct designs that motivate the behaviors that are intended for success.

CWA is a method from human factors engineering that takes a deep approach to the analysis of work processes [21]. CWA looks at the relationships that people must understand, the key tasks they must perform, and when work is analytical or aided by experiential rules and strategies. CWA creates a supportive information systems design that clarifies complex relationships for users, allows them to develop correct mental models, and encourages the development of effective strategies. CWA's design approach, Ecological Interface Design (EID), takes a relatively passive approach of visually showing information and relationships, relying on the user to pick up the information and execute appropriately. Over time, CWA changes behavior by gradually improving the user's understanding of the work environment and increasing the strategies they can use to solve work problems [3].

CWA is a framework that assists designers to analyze complex socio-technical systems and derive a set of design implications for developing such systems. Using this framework, designers can design for unanticipated events by constraining and narrowing down the actors' options and thus shaping their behavior and making the process of decision-making simpler at the time of unpredicted events [15]. CWA has always had the idea of "behavior-shaping" at its core, promoting a view of users as being able to good behaviors, when given the right information to do so. This view is in contrast to task analytic human factors methods which take a prescriptive approach to changing human behavior and believe the user must be constrained along a certain optimized behavioral path. Figure 1 shows the concept of persuading a 
behavior back into the effective space as defined by the CWA. For effective user behavior, there is always a space of good options (the shaded area). Ineffective behaviors can be viewed as behaviors outside of this space (the arrow outside the pentagon). CWA can be used to understand the space of effective action better. The pentagon in gray shows that effective space and the straight sides shows the constraints or boundaries on effective action identified by the CWA. PD can be used to push behavior back into the effective space.

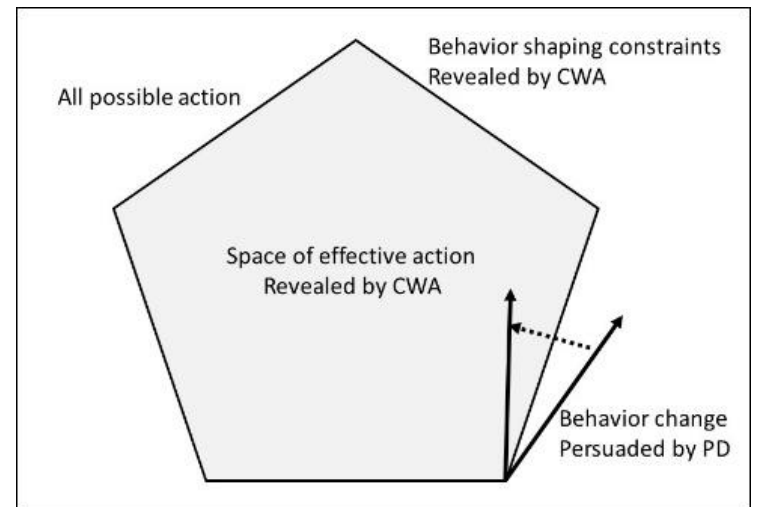

Figure 1. Moving into an effective action space with the persuasive design.

These ideas that CWA could benefit from a persuasive approach emerged when we began to study healthcare systems [2]. CWA has shown past success in the design of healthcare systems, often resulting in displays that show information in more usable ways [7]. For example, Wu, Jeon, Cafazzo, and Burns [21] conducted a WDA for designing an interface for radiotherapy monitoring systems, and based on their analysis; they made interface design recommendations to improve patient safety. Another example is the work of Gorges, Burns, Morita, and Ansermino [5], who performed CWA to elicit the design requirements of a patient monitoring system interface, aimed to assist clinicians in intensive care units. Most of the applications of CWA have been oriented towards clinician support.

\section{Cognitive Work Analysis and Behavior Shaping}

CWA arose from the context of nuclear power in the 1970's and 1980's [10, 11, 12, 21]. At this time, power plants were experiencing a rash of incidents. Engineers, trying to understand the causes of these incidents, became aware of several key problems. First, the plants were growing so complex that the operators could in reality never understand all the environmental factors and influences on their operations. Secondly, the best operators showed deep understanding and flexible behavior patterns that allowed them to solve problems effectively [10]. Procedural approaches, that specified normative behaviors were not resilient enough to handle the nearly infinite number of problems that operators were facing. As a result, the engineers working to support human performance in these complex work environments began to develop approaches that would guide behavior in effective ways, without being so rigid as to specify particular behavior paths. The goal became to understand the behaviors of the best operators and show these behavior approaches to the novice operators. The intention of this approach was to use technology to progress novice operators to operate more like highly experienced expert operators [3].

Following from these goals, CWA emerged as a potential approach [21]. CWA offered a five lens view on work, and the idea was that these lenses, together, would present a rich view of human work in these complex work systems. The first lens CWA offered was Work Domain Analysis. A work domain analysis looks at the context of the problem. It is called a means-end analysis, in that it specifies the goals of the work context, and connects those goals to what is available in the context to meet those goals. A work domain analysis looks at the purposes of the environment, the principles that drive that environment, the processes that occur, the components that exist in that environment and finally describes the pertinent aspects of those components [10]. While originally intended to be a very physical analysis for engineered systems, the model has extended well to contexts where intentions, values, and human processes may play the primary roles in the work context. The intention of a work domain analysis is to show how the system works optimally, and where breakdowns may occur. A failure of a human action, a violation of a closely held principle, or a weakened psychological state can be as influential on system behavior as a mechanical breakdown of a component.

The decision ladder provides the second view of human behavior. The decision ladder examines human information processing during key tasks [11]. The decision ladder has always been used flexibly to show alternative behavior paths that vary by the information processing states that are involved. For example, people facing a problem for the very first time may need to engage in deep decision making before choosing their next action. 
However, with experience, they may be able to recognize the situation and move directly to the appropriate behavior. A decision ladder is used to identify the triggers for various behavior paths and then to map out how people follow those paths.

The strategy analysis is the third lens of CWA. The strategy analysis looks at behavior options in different contexts, which is more appropriate and what are the triggers for different pathways [12]. For example, a strategy analysis would look for differences between expert and novice operators [2]. Another contextual difference that is often examined is workload level; if workload levels are very heavy, people often employ different strategies than when workload levels are low.

CWA has always had at its core a desire to support flexible behaviors and to guide people into more effective behaviors in the workplace. The strength of CWA is that it develops rich environmental models and that the method looks at different behavior paths, the context and the triggers for those paths. As CWA moves from engineering environments to more intentional, human environments, we have seen that it still holds potential to identify key factors for understanding behavior. In designing for support systems for human health, for example, CWA has been useful for identifying the physiological parameters to display, understanding how patients and clinicians adjust their work behaviors [2], and understanding how various motivators may influence behavior.

However, a weakness of CWA is that it is quite passive in its approach to behavior change. The design approach from CWA is Ecological Interface Design. The premise of Ecological Interface Design is that by showing users the various options and constraints on their behavior, they will eventually learn to manage effectively and demonstrate the desired behaviors [3]. Research has confirmed these premises to be true. Ecological Interface Design, however, could be improved by a more active approach to behavior change.

\section{Persuasive Design}

PD is an approach to the design of computer systems that explicitly seeks to change or influence human behavior. PD can be considered a step beyond user-centered design; while good usability is important for a successful design, for a design to be persuasive, it needs to have specific design features planned to create new behavior patterns.

PD draws on psychological and sociological principles to motivate behavior change. Some of these principles are well-known, for example, incentive schemes to motivate behavior. Other approaches take advantage of a user's desire for self-efficacy, or to contribute to a group. As a result, persuasive technologies may incorporate a variety of approaches from rewards and gamification techniques, to coaching and social competition.

PD refers often to the concept (modified from the original in Figure 2) that a particular behavior can be triggered if the user is properly motivated and their ability to perform the behavior is high enough. This model works as threshold model, essentially saying that the behavior triggers once the conditions are right. While this model makes sense intuitively, understanding when the conditions are right to trigger a new behavior, what that trigger should be, and what that new behavior should be can be challenging.

\section{Using CWA and PD together}

Persuasive Design is a set of techniques that can be applied to help individuals adopt new behaviors, or adapt their current behavior [8]. CWA, in contrast, emerged from a control theoretic engineering perspective and theories of analytic decision making and information processing. While they come from different perspectives, both frameworks are intended to develop effective behavior. Both frameworks also acknowledge that sometimes human behavior is not effective, and the user needs to be guided to more effective action. We develop the argument in this next section that these two approaches can aid each other, and there may be advantages to considering them together in a joint design approach.

Oinas-Kukkonen \& Harjumaa [9] developed the Persuasive System Design (PSD) framework. They state that "without carefully analysing the persuasion context, it will be hard or even impossible to recognize inconsistencies in a user's thinking, discern opportune and inopportune moments for delivering messages, and effectively persuade." The authors continue by describing the importance of recognizing the intent of persuasion, understanding the persuasion event, and defining the strategies to use. The value of understanding the use context, user context, and technology context of persuasion is highlighted. The PSD model helps identify how a user may be persuaded but requires a design to answer who the users are, and why the change is required to build an appropriate persuasion context.

Alahäivälä \& Oinas-Kukkonen [1] noted that studies often fail to provide a systematic analysis of contextual factors and that systematic analyses of the persuasive contexts have been lacking. This gap 
was also highlighted by Fogg in 2009, who suggested that there are not many well-defined processes for designing persuasive technology and that practitioners regularly adapt methods from other fields. Our proposition, therefore, is that CWA can provide a way to understand persuasive context. By identifying the behavior shaping constraints for successful behavior, CWA can identify behavior directions that could be encouraged through PD. By providing design approaches that can change behavior, ecological designs developed by CWA could be made more effective.

There are situations where the user's behavior is well understood, and the nature of the behavior change that is desired may be quite clear. In these situations, it makes sense to use additional design techniques to aid behavior further. PD [4] fits well with CWA and make behavior change a more actively designed intent. PD argues that to change behavior, one must put the appropriate triggers in the path of motivated users. This approach has three components, developing the motivated user, understanding where their path is (and where you want to move them to), and understanding what the appropriate triggers are. We propose that CWA and PD can be combined to develop a stronger design approach for deliberate behavior change.

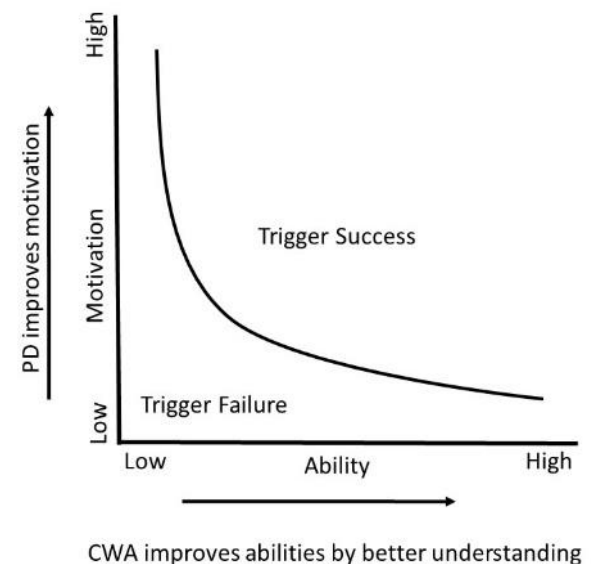

Figure 2. How CWA can help with understanding while PD can help with triggering behavior.

In the following section, we will discuss the problem of blood pressure management. This problem is the first problem that drew our attention to PD and its ability to compliment CWA. We have expanded and refined our interpretation of the problem. The problem is discussed in terms of developing a motivated user, understanding the behavioral change, and understanding the use of triggers in this context. In each case, the CWA model that can help to define the persuasive context is discussed.

\section{An Example of Blood Pressure Management}

Managing blood pressure is a complex control problem with similarities to other domains where CWA has been applied successfully [6, 20]. With its emphasis on understanding the work domain, CWA should reveal some of the knowledge requirements for successful blood pressure control. However, successful blood pressure management is more than a control problem and often requires the patients to make significant behavior changes such as modifying how they eat, exercise, and take medication to manage the condition [16]. While it is reasonable that patients will improve their management as they learn more about the condition, merely giving them a strong cognitive model of how hypertension occurs is not likely to motivate change. However, by combining CWA with PD, we can identify key pathways of behavior change that make sense to motivate.

\subsection{Developing the Motivated User}

The intention of the work domain analysis is to identify the functions and relationships required to achieve the purpose of the system, in this case, maintain a normal blood pressure (Table 1).

\begin{tabular}{|l|l|l|}
\cline { 2 - 3 } & \multicolumn{1}{|c|}{$\begin{array}{c}\text { Whole system } \\
\text { (Patient) }\end{array}$} & \multicolumn{1}{|c|}{$\begin{array}{c}\text { Subsystem } \\
\text { (Body Systems) }\end{array}$} \\
\hline $\begin{array}{l}\text { System } \\
\text { Purpose }\end{array}$ & $\begin{array}{l}\text { Maintain blood } \\
\text { pressure in normal } \\
\text { range }\end{array}$ & $\begin{array}{l}\text { Maintain blood } \\
\text { pressure in normal } \\
\text { range }\end{array}$ \\
\hline $\begin{array}{l}\text { Principles, } \\
\text { Priorities } \\
\text { Balances }\end{array}$ & $\begin{array}{l}\text { and } \\
\text { andinciples of Human } \\
\text { body for regulating } \\
\text { blood pressure } \\
\text { Valuing healthy life }\end{array}$ & $\begin{array}{l}\text { Underlying laws and } \\
\text { principles of } \\
\text { patient's: Circulatory } \\
\text { system, Nervous } \\
\text { system, Endocrine } \\
\text { system, Cognitive } \\
\text { system, Self- }\end{array}$ \\
\hline & regulatory system \\
\hline
\end{tabular}




\begin{tabular}{|c|c|c|}
\hline $\begin{array}{l}\text { Processes } \\
\text { (Physiological } \\
\text { and Non- } \\
\text { Physiological } \\
\text { Processes) }\end{array}$ & $\begin{array}{l}\text { Taking medications } \\
\text { according to the new } \\
\text { prescription, } \\
\text { Following } \\
\text { physicians' } \\
\text { instruction regarding } \\
\text { diet or physical } \\
\text { activity }\end{array}$ & $\begin{array}{l}\text { Physiological } \\
\text { processes in patient's } \\
\text { body (Regulated by } \\
\text { circulatory system, } \\
\text { nervous system, } \\
\text { endocrine system) } \\
\text { Psychological } \\
\text { processes (Cognitive } \\
\text { processes } \\
\text { determining person's } \\
\text { behavior and choices } \\
\text { at each moment) } \\
\text { Pharmacological } \\
\text { processes of the } \\
\text { prescribed drug } \\
\text { (Diuretic, beta- } \\
\text { blocker, ACE } \\
\text { inhibitor, etc.) } \\
\text { Metabolism of food } \\
\text { and processes } \\
\text { associated with food } \\
\text { nutrients }\end{array}$ \\
\hline $\begin{array}{l}\text { Physical } \\
\text { Function }\end{array}$ & $\begin{array}{l}\text { Patient body } \\
\text { Medication Food }\end{array}$ & $\begin{array}{l}\text { Circulatory system } \\
\text { (Heart, blood, blood } \\
\text { vessels) Endocrine } \\
\text { system Nervous } \\
\text { system } \\
\text { Ingredients of Active } \\
\text { Medication Active } \\
\text { Ingredients of Food }\end{array}$ \\
\hline $\begin{array}{l}\text { Physical Form } \\
\text { (patient and } \\
\text { equipment) }\end{array}$ & $\begin{array}{l}\text { Age, Weight, } \\
\text { Gender, Race of the } \\
\text { patient Patient's } \\
\text { regulatory focus and } \\
\text { mood Medication } \\
\text { type and dose Food } \\
\text { type and amount }\end{array}$ & $\begin{array}{l}\text { Blood pressure level, } \\
\text { Heart rate and } \\
\text { condition Blood } \\
\text { vessel condition, } \\
\text { Psychological status } \\
\text { Medication type and } \\
\text { dose Food type and } \\
\text { amount }\end{array}$ \\
\hline
\end{tabular}

Table 1. A work domain analysis for blood pressure management.

While the work domain analysis identifies the physiological components for blood pressure management, which would be typical for a work domain analysis. We have included some behavioral components that are important for the behavioral success of blood pressure management. These include regulatory focus and mood, the following of instructions on diet and activity, compliance with medications, and values for health.

Work domain analysis shows how a system should be configured to operate optimally, and the components modeled in the analysis, show potential failure points of the system. By including behavioral change as well as physiological components, this indicates that while medications or diet may be important to control for healthy blood pressure, cognitive processes mood and values may also need to operate ideally for the patient to manage their condition. The work domain analysis builds a broad contextual model of the requirements for success.

\subsection{Choosing a Behavioural Path to Change}

There are two analyses in CWA that identify different behavioral paths. The first is the decision ladder and the second is the strategy analysis.

The decision ladder (Figure 3) looks at human decisions in terms of cognitive processing. Essentially the ladder is an information processing template that can be used to identify when people must undertake complex decision making, and where they may take advantage of rules, and heuristics to decide the next course of action more quickly. Operating by these rules and heuristics is cognitively less effortful but is more typical of highly experienced users.

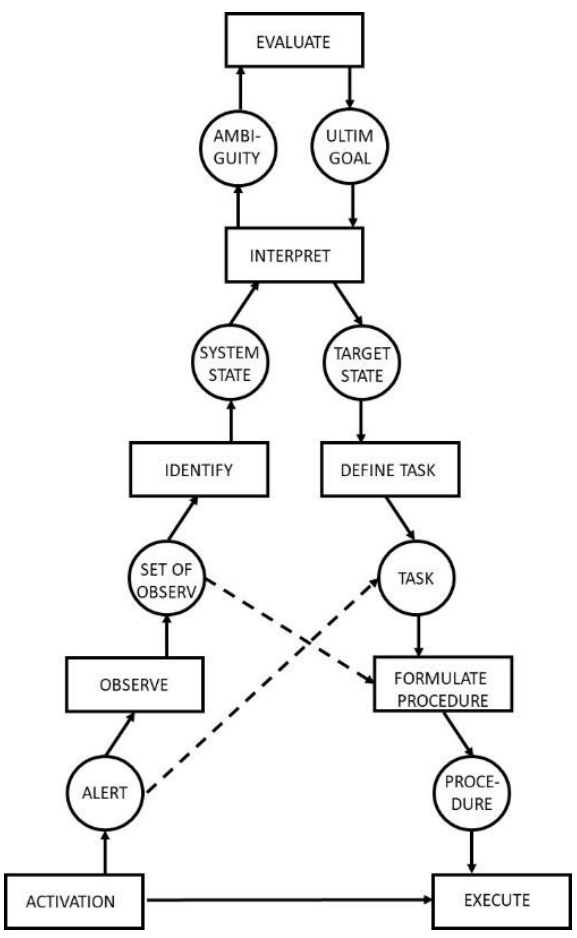

Figure 3. A typical decision ladder showing shortcuts from heuristics.

A CWA would identify the rules and heuristics of experienced users and, through design, try to encourage less experienced users to adopt these new pathways. Taking the path of a more experienced user is one sort of path that might be accessible for behavior change [18]. In Figure 4, we give a simple example in blood pressure management. In this case, the user may be undergoing a process of 
assessing their options on whether they should measure their blood pressure (the solid black line from "observe" to "decision making stages"). It may be desirable to take this option consideration behavior away and instead build a habit (the dashed line from "observe" to "task"). The definition of habit we are using is the Merriam-Webster: a routine of behavior that is repeated regularly and tends to occur subconsciously. In this case, the habit trajectory would look like "Its 7 pm, time to measure my blood pressure". This behavior path change is shown in Figure 4. The dashed line shows the behavior trajectory, avoiding the conscious decision making stages of the previous pattern. This would be the first step of establishing a habit.

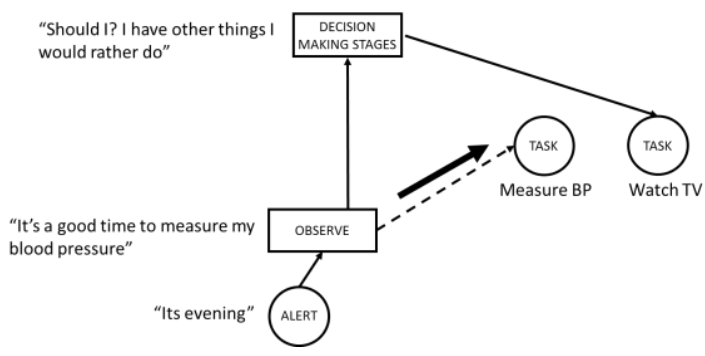

Figure 4. Changing a behavior path as discovered using the decision ladder.

\subsection{Understanding the Triggers}

The final contribution is to identify where and when a trigger should be added [17]. The information system design can be tuned to add new information to encourage a particular path. Following the same example as before (Figure 4), the trigger can be strengthened and made more specific "Let's measure your blood pressure," and the cognitive process can be simplified - the user no longer needs to check the time, and then remember to take action. This development of a trigger, to make the path even more persuasive is shown below in Figure 5. The trigger added here is a notification, which takes away the task of the user to monitor their time, to initiate the behavior of measuring their blood pressure.

In this case, we know that the "alert" stage must occur for the user to initiate the measurement of their blood pressure. We are taking advantage of this alert stage to refine it through design. Instead of expecting the user to monitor the time, and alert themselves (the pattern on the left), a timed notification reduces the users workload at the alert stage. The alert stage can be used further to provide a message that indicates the behavior pathway we want to occur "Let's measure your blood pressure".

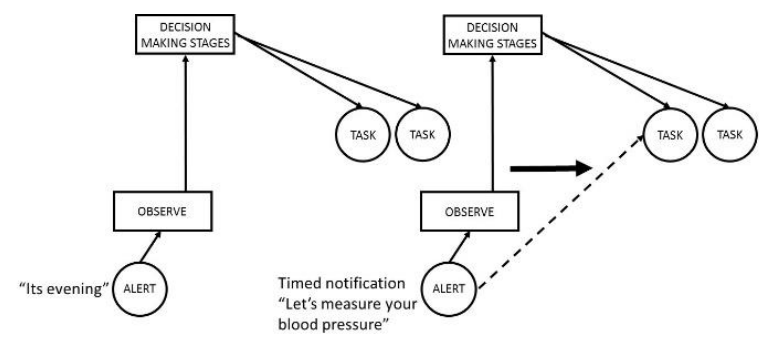

Figure 5. Creation of a notification to persuade behavior change further.

\section{Conclusion: Designing for Behavior Change}

We are proposing that a PD approach can work in concert with CWA. PD enhances CWA by providing active motivation for behavior change, beyond the relatively passive approach of ecological interface design. CWA can enhance a PD approach by identifying target behaviors to change.

From the work domain analysis, behavior change requirements can be identified such as 1) understanding the mood, regulatory focus, and capabilities of the user, 2) identifying the values of the user and 3) identifying when the user is making the system work less effectively. Mood, regulatory focus and capabilities can help to identify the best suited persuasive technique or provide tailoring of the design. The values of the user may help to motivate behavior change $[14,15]$. Understanding where the user's actions are influencing the system negatively can help to identify the behaviors that are needed for change.

From the decision ladder one can specifically identify current and preferred behavior paths for change. The information needed to make the action easier to perform can be identified and we can understand how to improve the design of triggers and where to place them. The strategies analysis contributes in the same manner. This information is summarized in Table 2. 


\begin{tabular}{|l|l|}
\hline CWA component & Contribution to PD \\
\hline Work domain analysis & $\begin{array}{l}\text { Understanding user capabilities } \\
\text { Understanding user mood } \\
\text { Identifying user values }\end{array}$ \\
\hline Decision ladder & $\begin{array}{l}\text { Current behavior paths that need redesign } \\
\text { Improved behavior paths } \\
\text { Information to design better triggers }\end{array}$ \\
\hline Strategy analysis & $\begin{array}{l}\text { Current behavior paths that need redesign } \\
\text { Improved behavior paths } \\
\text { Information to design better triggers }\end{array}$ \\
\hline
\end{tabular}

Table 2. Design contributions of CWA to PD.

These ideas have been developed and refined over several projects but brought together for the first time here $[13,14,17,18]$. In an early project on blood pressure monitoring by patients [13], we developed the work domain analysis in Table 1 and began to see the first connections between CWA and PD. The idea of identifying a user's regulatory focus and using that for the tailoring of persuasive messages is currently under investigation [13, 14]. In this work, the user's regulatory focus is identified and then messages are presented to them that fit or don't fit their regulatory focus to encourage fitness. At this time the study is ongoing. St. Maurice used the decision ladder to identify behavioral paths [18, 19]. A persuasive intervention was designed to improve data entry behavior [17]. The intervention significantly improved data entry behavior and showed a sustainable change in behavior over time. A PD approach is adding benefit to CWA based designs, and changes in behavior are measurable.

There are many social and environmental factors that contribute to behavior change or to sustain a healthy behavior. Therefore, the effectiveness of behavior change systems that are designed solely based on persuasive design principles and do not account for complex environmental factors (factors that can cause relapses) has not been well verified. It is crucial to conduct a thorough analysis of the users' (psychoand physiological) characteristics, and also many other factors that affect them in the process of behavior change [14]. To this date, behavior change support systems that take into account social/environmental elements have not been investigated extensively. The PD framework informed by CWA equips the system designer with an effective tool to consider all the parameters that could play a role in the behavior change journey.

In this article, authors described few examples to help readers to understand how a BCSS system whose design is informed by CWA, can work more effectively. According to Siegle (2005), one of the barriers to effectively control one's blood pressure can be mitigated by increasing ease of medication renewal [16]. Therefore, applying EID in combination with PD principles is necessary to make a more effective behavior change system. Using tempo-spatial parameters in the design of the system to provide users with timely reminders would be beneficial when they are near a pharmacy, and their medication renewal date is close.

Similarly, designing behavior change systems that keep track of individuals' blood pressure readings can use historical and real-time data to identify situations that may potentially increase the users' blood pressure, and therefore provide users with suggestions and strategies that help to keep their blood pressure in a normal range. In the age of ubiquitous computing, sensors have the potential to detect many environmental factors that may be behavior triggers.

All these examples shed light on the fact that designing behavior change support systems that consider users as the only actors would not function as effectively, as those systems that take into account the environmental variables affecting the users' mental or physical condition. In general, it is important to realize that conducting a thorough analysis can help system designers to understand the potential threats which can cause a relapse. CWA can contribute to the practice of PD by contributing a systematic way of determining the environmental triggers and contexts and how they play a role in behavior change.

\section{Acknowledgements}

The writing of the paper was supported by the Natural Sciences and Engineering Research Council of Canada (NSERC) Discovery Grant \#132995.

\section{References}

[1] T. Alahaivala, and H. Oinas-Kukkonen, "Understanding persuasion contexts in health gamification: A systematic analysis of gamified health behaviour change support systems literature", International Journal of Medical Informatics, Elsevier, 2016 (96), pp.62-70.

[2] M. Ashoori, C.M. Burns, K. Momtahan, and B. d'Entremont, "Using team cognitive work analysis to reveal healthcare team interactions in a labour and 
delivery unit", Ergonomics, Taylor and Francis, 2014 (57) pp. 973-986.

[3] K. Christoffersen, C.N. Hunter, and K.J. Vicente, "A longitudinal study of the effects of Ecological Interface Design on skill acquisition”, Human Factors, Sage, 1996 (38), pp. 523-541.

[4] B.J. Fogg, "A behaviour model for persuasive design", Proceedings of the $4^{\text {th }}$ International Conference on Persuasive Technology, ACM, 2009, p.40.

[5] M. Gorges, P. P. Morita, C.M. Burns, and M. Ansermino, "Mobile Patient Monitoring for the Pediatric Intensive Care Unit - Work Domain Analysis and Rapid Prototyping Results”, SMC 2013: The International Conference on Systems, Man and Cybernetics, IEEE, 2013, pp. 3765-3770.

[6] J.R. Hajdukiewicz, K.J. Vicente, D.J. Doyle, P. Milgram, and C.M. Burns. "Modeling a medical environment: An ontology for integrated medical informatics design", International Journal of Medical Informatics, Elsevier, 2001, 62, pp. 79-99.

[7] T. Jiancaro, G.A. Jamieson and A. Mihailidis, "Twenty years of Cognitive Work Analysis in Health Care A Scoping Review", Journal of Cognitive Engineering and Decision Making, SAGE, 2013, 8(10) pp.3-22.

[8] H. Oinas-Kukkonen, "Behavior change support systems: A research model and agenda", International Conference on Persuasive Technology, Springer, 2010 4-14.

[9] H. Oinas-Kukkonen, and M. Harjumaa, "Persuasive systems design: Key issues, process model and system features", Communications of the Association for Information Systems, ACM, 2009 (24), pp.485-500.

[10] J. Rasmussen, and A. Jensen, "Mental procedures in real-life tasks: A case study of electronic trouble shooting", Ergonomics, Taylor and Francis, 1974 17(3), pp. 293-307.

[11] J. Rasmussen, J., "Outlines of a hybrid model of the process plant operator", Monitoring Behavior and Supervisory Control (Eds: Sheridan, T. and Johanssen, G.) Plenum Press, NY., 1976. pp. 371-383.

[12] J. Rasmussen, "Skills, rules, knowledge; signals, signs, and symbols, and other distinctions in human performance models", IEEE Transactions on Systems, Man and Cybernetics, IEEE, 1983 (13) pp.257-266.
[13] L. Sadat Rezai, and C.M. Burns, "Using Cognitive Work Analysis and a Persuasive Design approach to create effective blood pressure management systems ", HFES 2014 International Symposium on Human Factors and Ergonomics in Health Care, HFES, 2014 (3), pp.3643.

[14] L. Sadat Rezai, J. Chin, R. Bassett-Gunter, C.M. Burns, "Developing persuasive health messages for a behaviour-change-support-system that promotes physical activity", Adjunct proceedings of Persuasive Technology XII, Amsterdam, NL, April 3-6, 2017, pp. 21-25.

[15] L. Sadat Rezai, J. Chin, R.Bassett-Gunter, and C.M. Burns, "Motivating people to perform physical activity", HFES 2017 International Symposium on Human Factors and Ergonomics: Shaping the Future., HFES, New Orleans. March 6-8. 2017, pp.89-95.

[16] D. Siegel, "Barriers to and strategies for effective blood pressure control", Vascular Health Risk Management, 2005 (1), 9-14.

[17] St. Maurice, J., "Improving data quality in primary care: Modelling, measurement, and the design of interventions" PhD dissertation. University of Waterloo. April 2017.

[18] J. St. Maurice, and C.M. Burns, "Using comparative cognitive work analysis to identify design priorities in complex socio-technical systems", 2015 International Symposium on Human Factors and Ergonomics in Health Care: Improving the Outcomes, HFES, 2015, 4(1), pp. 118-123.

[19] J. St. Maurice, and C.M. Burns, "Using persuasive design to improve data-entry behaviour in primary care", Journal of Medical Internet Research, JMIR Publications, under review.

[20] L.K. Thompson, J. Hickson, and C.M. Burns, "WDA for Blood Glucose Management", Proceedings of the $47^{\text {th }}$ Annual Meeting of the Human Factors and Ergonomics Society, HFES, pp.1516-1520.

[21] Vicente, K.J. Cognitive Work Analysis: Towards safe, productive, and healthy computer-based work. Lawrence Erlbaum and Associates, Hillsdale, NJ, 1999.

[22] L. Wu, J. Jeon, J. Cafazzo, J., and C.M. Burns. Applying Ecological Interface Design to improve the control interface for radiotherapists. 2012 Symposium on Human Factors and Ergonomics in Health Care: Bridging the Gap, HFES, Baltimore, MD, March 12-14, 2012. 